16. A T Atto et al., J. Soc Leather Trades Chem., 55 (1971) 163.

17. K H Gustavson. J. Amer. Chem. Soc., 74 (1952) 4608.

18. K T Joseph et al., Arch. Biochem. Biophys., 74 (1958) 46.

19. K H Gustauson. The chemistry and reactivity of collagen (New York: Academic Press, 1956) 250.

20. F Karush, J. Amer. Chem. Soc., 72 (1950) 2705.

21. T Vickerstaff, The physical chemistry of dyeing (London: Oliver and Boyd, 1950) 89.

22. C H Giles, Chem. Ind., (3) (1966) 92

23. K H Gustavson. Acta Chem. Scand., 6 (1952) 1443.

24. F R Hartley, Aust. J. Chem., 23 (1970) 287

25. F R Hartley. J.S.D.C. 85 (1969) 66.
26. K Shirai et al., Proc. 19th Congress of the International Union of Leather Technologists and Chemists Societies, Melbourne (1987) 330 .

27. K H Gustauson et al., J. Soc. Leather Trades Chem., 39 (1955) 107 .

28. $Z$ A Siddiqui et al., Proc. Seminar on Vegetable Tannins, Ed. S Rajadurai and K Udaya Bhanu (Madras: CLRI, 1962) 137.

29. W E Braybrooks et al., J. Soc. Leather Trades Chem., 23 (1939) 111.

30. The chemistry and technology of leather, Vol. 3-Process control of leather quality, Ed. F O'Flaherty and W T Roddy (New York: Reinhold Publishing, 1962) 27, 28.

\title{
Foam application from a closed system - a study of machine and foam parameters
}

\author{
Jacques T E Lemmen and Jan Groot Wassink
}

University of Twente, Enschede, The Netherlands

An attempt has been made to gain a greater insight into the interaction between foam and a moving textile substrate. The effects of changing wet pick-up, fabric velocity, liquid viscosity, foam density and mode of application on penetration have been studied. Application from a closed system makes it possible to apply an exact amount of liquid, and reflectance measurements revealed that between 10 and $60 \%$ wet pick-up the actual level of wet pick-up is of major importance. The amount of liquid available determines the likelihood of capillary transport. The results obtained in terms of fabric speed and foam density still leave questions to be answered on the mechanisms of foam flow and degradation in the textile.

\section{INTRODUCTION}

In recent decades foam application has been quite commonly used in the textile wet processing industry as a low add-on technique. Foam is used to apply chemicals and colorants to textiles because only a small amount of water is required, resulting in lowered energy demand during drying. Other possible advantages include higher production speeds, a lower demand for chemicals and improvement in product quality. The two last-mentioned advantages make the investigation of the transport phenomena of water and foam in the textile substrate very worthwhile.

The present research is part of a broader investigation into transport phenomena in textile finishing equipment with special attention being paid to the interaction between foam and substrate. This interaction is studied in relation to foam and machine parameters. Application is carried out with a rotary-screen printing machine on which foam is applied to the fabric from a closed system by means of an applicator slit. The parameters under investigation are quoted in Table 1.

With the exception of foam density $\left(\rho_{s}\right)$ all the variables mentioned are also of great importance in conventional application processes (e.g. dyeing and printing). The wet pick-up and viscosity $(\eta)$ are of importance in every finishing process because they determine where and to what extent the transporting medium can flow and where, in the first instance, the chemicals will be located. The group of interconnected variables fabric velocity $(v)$, contact length $(I)$ and contact time $\left(t_{c}\right)$ is also very significant. In processes in which the fabric is completely immersed, the time during which immersion takes place is influential in determining the extent to which wetting and exchange of matter can occur. In continuous printing processes velocity and contact length influence the pressure at which the printing paste is pressed through the screen, and thus affect the net result.

Effects of a similar nature may be expected to occur when using foam. On foaming a liquid system a new flowing medium is introduced for at least a part of the process. This foam has different rheological properties, dependent on foam density and bubble size distribution. As well as this different flow behaviour, liquid transport from the foam phase to the capillary system of the substrate will be different from that occurring in a pure liquid.

Considerations based on conventional finishing processes, together with the influence of the foam medium, led to a series of experiments studying the parameters men-

TABLE 1

Parameters studied and their variation

\begin{tabular}{lc} 
Parameter & Range \\
\hline Wet pick-up & $15-60 \%$ \\
Viscosity & LS20/LS30 \\
Foam density & $100-333 \mathrm{~g} /$ \\
Velocity & $6.7-25 \mathrm{~m} / \mathrm{min}$ \\
Length & $2.25,5.5$ and $18.2 \mathrm{~mm}$ \\
Contact time & $5-50 \mathrm{~ms}$
\end{tabular}


tioned in Table 1. Up to this point the study had a qualitative nature because the assessment of the results had no clear quantitative relationship to the parameters studied. Evaluation of the results was done in two ways, i.e. visually on the basis of printing results of patterns and by measurement of the reflection of substrates treated both with and without a screen. The purpose of this set-up was to obtain a clear picture of the influence of the parameters studied and thus derive a model to describe the flow of foam and liquid in textiles.

\section{EXPERIMENTAL}

The foam application experiments were carried out on a laboratory rotary-screen printing machine. Three configurations were possible: application through a printing screen (80 mesh), through a coating screen (125 mesh) and without a screen, directly on the fabric. Foam generation was carried out in a rotor-stator mixer having a rotor diameter of $132 \mathrm{~mm}$, a rotor-stator distance of $1 \mathrm{~mm}$ and run at a rotational speed of approximately $1400 \mathrm{rev} . / \mathrm{min}$. Starting with a liquid flow of $1 \mathrm{l} / \mathrm{min}$, air was supplied to produce a foam having a density of 100 to $333 \mathrm{~g} / \mathrm{l}$.

The foam was applied to the substrate via a plastic slit that was placed either directly onto the fabric or fixed on the inside of a rotary screen. Three different slits were used with the dimensions:

$$
\begin{array}{cccc}
-18.2 \times 58.2 \times & \times & 14.0 \mathrm{~mm} \\
- & 5.5 \times 58.4 \times & 20.5 \mathrm{~mm} \\
- & 2.25 \times 54.2 \times & 19.5 \mathrm{~mm} .
\end{array}
$$

Height was not considered to be of importance, but a correction was introduced for width, which is really nothing but a scale-up parameter. We chose for foam application a width of about $5.5-6 \mathrm{~cm}$ because the distribution of foam at greater widths causes a problem of dye uniformity over the width. The origin of this problem is the pseudoplastic nature of foam combined with the compressibility of the gas phase. At a width of about $6 \mathrm{~cm}$ the pressure drop over this width is so small that no appreciable influence was expected.

From the mixer the foam was transported through a pipe positioned in the rotary screen. This pipe could be short-circuited with the applicator slit via a $10 \mathrm{~mm}$ high and $0.1-0.2 \mathrm{~mm}$ wide foam supply slit. The major part of the foam produced was removed through a drain and only $1-5 \%$ was applied to the fabric, in order to maintain an almost constant pressure level in the pipe that was hardly influenced by opening the supply slit (Figure 1).

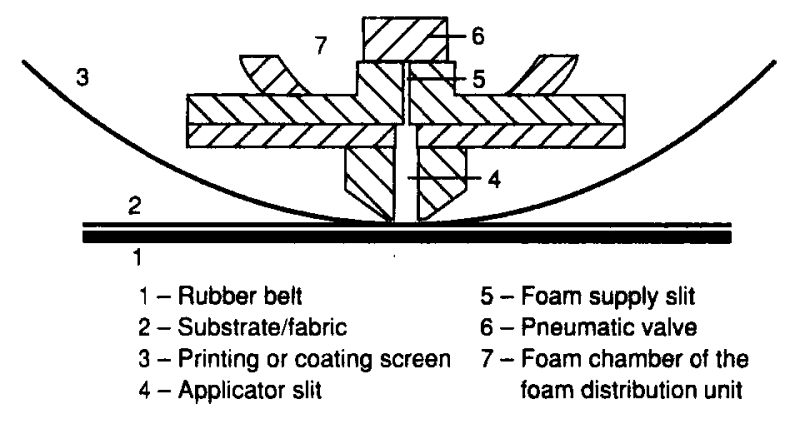

Figure 1 - Mode of foam delivery by a fixed applicator slit
The solutions used contained lauryl sulphate as the surfactant and were thickened by adding Solvitose, composition:

- Distilled water, $100 \mathrm{~kg}$

- Sodium dodecylsulphate (>99\%), $1 \mathrm{~kg}$

- Solvitose MVS-FN (Avebe), 2 or $3 \mathrm{~kg}$ (LS20/LS30).

A rather rough cotton quality was used, specifications of which were:

- Weight, $140 \mathrm{~g} / \mathrm{m}^{2}$ (dry)

- Warp, 2870 per m, $38 \mathrm{Nm}$

- Weft, 2140 per $\mathrm{m}, 36 \mathrm{~N} \mathrm{~m}$.

The dyes and their concentrations (Solphenyl Green 5BL (CGY, C.I. Direct Green 27), 4\% o.w.f., and Remazol Brilliant Green 6B (HOE, C.I. Reactive Blue 38), 12\% o.w.f.) were selected for the dyes' low affinity towards cotton, the possibilities they offered in evaluating the levelness (no spotty appearance) of the printing and because the colour intensity was sufficient to assess the printed motifs. The wet pick-up (the weight of water applied divided by the weight of fabric input under operational conditions, expressed as a percentage) was determined, neglecting the amount of solids in solution. On the one hand this was done by calculation using fabric velocity and liquid flow, on the other hand (up to wet pick-up levels of $30 \%$ ) by direct measurement of a sample before and after weighing. Data concerning the rheology of the foams used are presented in Table 2. The mean bubble diameter of the applied foams was about 30-40 $\mu \mathrm{m}$.

TABLE 2

Viscosity of foams used (measured at $D_{r}=300-1800 \mathrm{~s}^{-1}$ $\left.[7]^{(\mathrm{a})}\right)$

\begin{tabular}{lccccc}
\hline & \multicolumn{2}{c}{ LS20 } & & \multicolumn{2}{c}{ LS30 } \\
\cline { 2 - 3 } \cline { 5 - 5 } $\begin{array}{c}\text { Foam } \\
\text { density }\end{array}$ & $k(\mathrm{~Pa})$ & $n$ & $k(\mathrm{~Pa})$ & $n$ \\
& & & & & \\
\hline & & & & & \\
1000 & 0.44 & 0.69 & & 2.89 & 0.55 \\
333 & 4.52 & 0.52 & & 8.84 & 0.50 \\
200 & 8.21 & 0.47 & 14.5 & 0.45 \\
100 & 12.7 & 0.43 & 23.5 & 0.40 \\
& & & & & \\
\hline
\end{tabular}

(a) $\tau=k(D)^{n}$

\section{RESULTS}

\section{Wet pick-up}

One of the criteria used for determining the influence of wet pick-up was a visual judgement of the extent of coloration of a $1 \mathrm{~mm}$ wide line of a motif (printed through a printing screen) which was supposed not to be coloured at all. These results were categorised as either:

- Good (a sharp line that had the same width everywhere)

- Moderate ( $\mathrm{a}$ line with an unsharp boundary between coloration and non-coloration)

- Bad (largely or completely coloured). 
At a wet pick-up of $15 \%$ the print was thus qualified good, prints in the range 15-30\% moderate and above $30 \%$ bad. At wet pick-up levels from 30 to $60 \%$ the degree of coloration appeared to depend on the numerical value of the wet pick-up, while from 15 to $30 \%$ this seemed to be dependent on foam density.

The influence of wet pick-up was also studied in relation to the degree of penetration of the colorant. This was determined from reflectance measurements at $660 \mathrm{~nm}$ (minimal reflection), from which a degree of penetration $P$, expressed as a percentage, was calculated according to Eqn $1[1,2]$ :

$$
P=\frac{\ln \left(R_{\mathrm{x}}+\frac{1-R_{\mathrm{x}}^{2}}{R_{\mathrm{x}}-R_{\mathrm{e}}}\right)-\ln \left(R_{\mathrm{x}}+\frac{1-R_{\mathrm{x}}^{2}}{R_{\mathrm{x}}-R_{\mathrm{a}}}\right)}{\ln \left(R_{\mathrm{x}}+\frac{1-R_{\mathrm{x}}^{2}}{R_{\mathrm{x}}-R_{e}}\right)-\ln \left(R_{\mathrm{x}}+\frac{1-R_{\mathrm{x}}^{2}}{R_{\mathrm{x}}-R_{\mathrm{d}}}\right)} \times 100
$$

where $R_{\mathrm{x}}=$ reflection of the blank material

$R_{\mathrm{d}}=$ reflection of the coloured side of the substrate

$R_{\mathrm{a}}=$ reflection of the back of the substrate

$R_{e}=$ reflection of the coloured side of the substrate with one layer of blank material on top of it.

This definition assumes a homogenous, one-step concentration distribution of the colorant over the thickness of the substrate (Figure 2). The thickness $X$ of the reflecting layer follows from one of the solutions of the Kubelka-Munk equation containing the reflections mentioned above. The degree of penetration $P$ thus defined can be used for comparison of treated materials only when assuming an almost similar distribution of concentration over the thickness of the substrate.

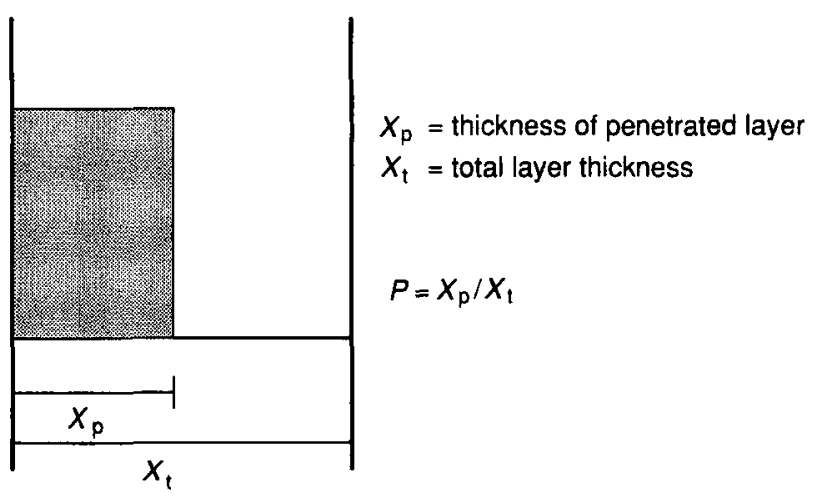

Figure 2-Definition of penetration

The results thus obtained are shown in Figure 3 and an increase of penetration as a function of wet pick-up can clearly be discerned. Almost complete penetration seems to be possible only when using about $60 \%$ water, comparable with the result of forced pressing on a foulard. Because this value is above the critical limit for capillary transport (for cotton about 30-35\%) this result was to be expected. On the other hand, when working significantly below the critical value for capillary transport a water deficiency leads to significantly less penetration. At first sight the penetration of liquid through the thickness of the substrate does not seem to be exceptionally improved by the use of foam during application. But the major importance of the absolute quantity of liquid available indicates a transport mechanism in the substrate that, very soon after applying the foam, is governed by the liquid contained in it instead of by the foam itself. This points to a relatively quick degradation of foam in the substrate.

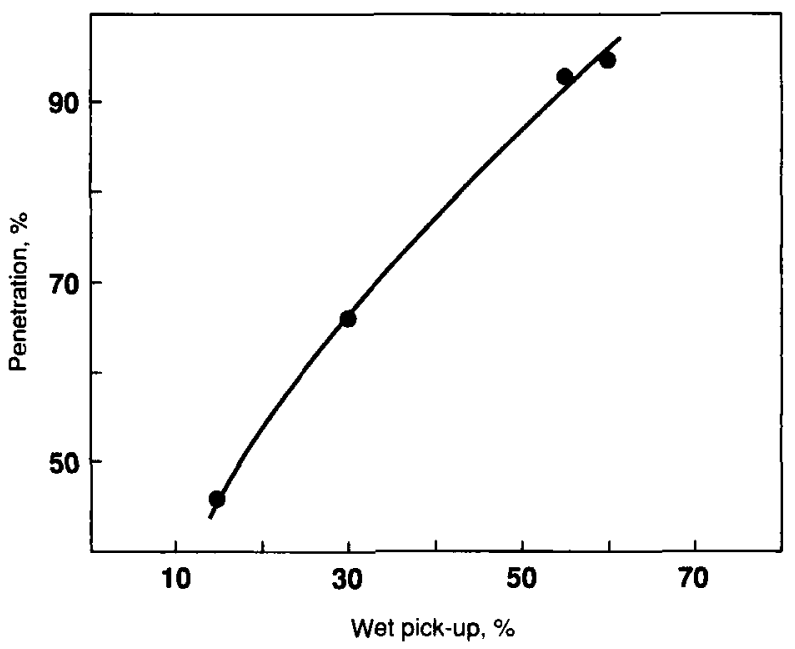

Figure 3 - Penetration as a function of wet pick-up $\Lambda=$ $2.25-5.5 \mathrm{~mm}, v=6.7 \mathrm{~m} / \mathrm{min}, \rho_{\mathrm{s}}=200 \mathrm{~g} / \mathrm{l}$, LS30, coating screen)

Other considerations also point in that direction. When applying a liquid $\left(\rho=1 \mathrm{~g} / \mathrm{cm}^{3}\right)$ onto a substrate of 150 $\mathrm{g} / \mathrm{m}^{2}$ about $200 \mu \mathrm{m}$ thick and with a gauze porosity (void volume between the yarn relative to the total volume of the fabric) of $30 \%$ [3] the voids between the yarns will be completely filled at a wet pick-up of $40 \%$. Foamed to a blow ratio (Eqn 2) of 4, complete filling already occurs at a wet pick-up of $8 \%$. Because even in the fastest processes wet pick-up levels far above $10 \%$ are experienced, the volume of foam applied will almost always be much larger than the volume available in the substrate. In closed systems with a free running fabric the foam may be pressed right through the fabric. When supported by a rubber belt some pressure may develop in the substrate that must be released behind the point of application at a wet pick-up of $60 \%$ when using foams of blow ratios of 4 or larger. A considerable degradation of foam must occur as the volume expansion can be $20 \%$ at most.

Two mechanisms of degradation may be responsible, i.e. collapse of the bubbles and drainage of the lamellae under the suction influence of the capillary system of the substrate. Collapse of the bubbles will certainly occur when shear forces are applied. At this point it should be noted that shear forces also occur in foam mixers and when flowing through structured substrates, e.g. screens. In those cases a change of structure of the foam may occur, e.g. a decrease in bubble diameter, but this does not necessarily lead to degradation.

The rate at which the foam can drain under the influence of substrate suction is limited, as is clear from the investigations of Bryant [4], who defined a dynamic sorp- 
tion rate in the absence of any external pressure drop across the substrate. Because of the short contact times $(0.02-0.05$ s) during the experiments illustrated by Figure 3 , it is possible that the 'substrate active' drainage does not have time to take place under atmospheric conditions. At given values of foam stability, velocity and wet pick-up it will be necessary to impose the required absorption rate by applying external pressure. This is possible because the pressures measured in the application slit (0.1-0.4 bar) are of the same order of magnitude as the capillary forces in the substrate (0.1 bar).

\section{Foam density}

Because of the low solids concentrations, the liquid density was assumed to be $1 \mathrm{~g} / \mathrm{cm}^{3}$, so the foam density can be expressed by Eqn 2:

$$
\rho_{s}=\frac{1}{B+1}
$$

where $B$ is the blow ratio, i.e. gas volume divided by the liquid volume. Most experiments were carried out at three blow ratios: 2, 4 and 9, resulting in the foam densities 333 , 200 and $100 \mathrm{~g} / 1$. For three experiments under different conditions the degree of penetration was measured as a function of foam density (Figure 4).

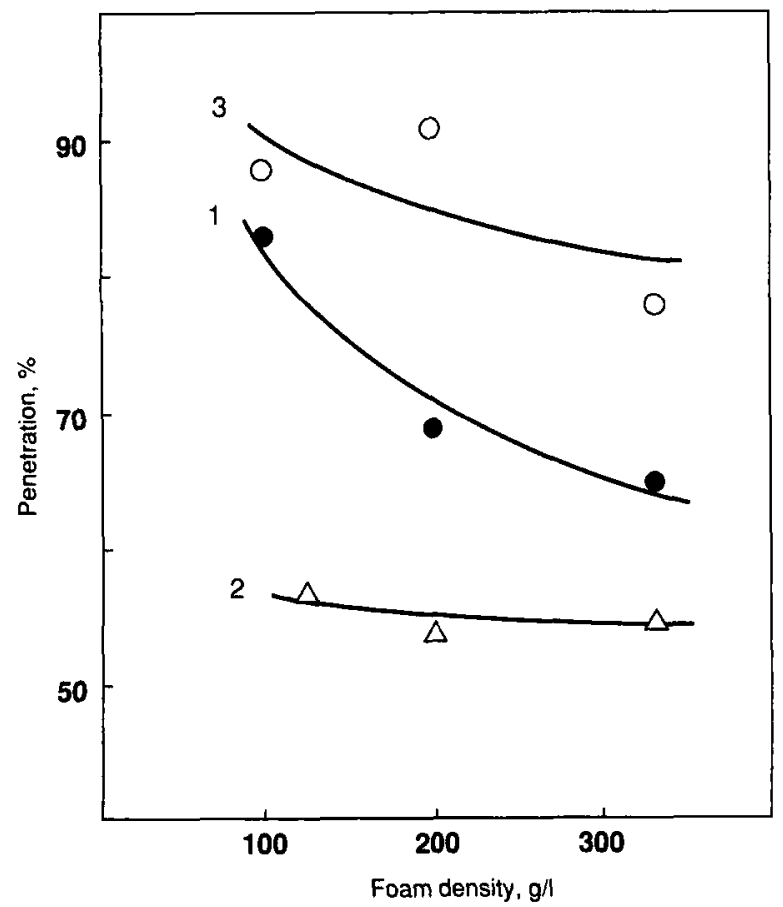

$1-I=2.25 \mathrm{~mm}, v=6.7 \mathrm{~m} / \mathrm{min}$, wet pick-up $=35 \%$, LS2O, coating screen $2-l=2.5 \mathrm{~mm}, \quad v=23 \mathrm{~m} / \mathrm{min}$, wet pick-up $=20 \%$, LS30, no screen

$3-l=5.5 \mathrm{~mm}, v=20 \mathrm{~m} / \mathrm{min}$, wet pick-up $=30 \%$, LS 30 , coating screen

Figure 4-Penetration as a function of foam density

Although the differences are not very distinct, there is some indication that the degree of penetration increases when the foam density decreases. This information is complementary to the considerations concerning wet pick-up and the ratio between foam volume and open fabric volume (Figure 3). The foam density is lower in a closed system under identical (e.g. constant wet pick-up) conditions; this means that only the gas flow will increase. Thus the volume ratio of foam to open fabric increases, as does the pressure in the application slit and the fabric. The extra pressure can be used to force the liquid into the capillary system of the substrate and also to enhance the degree of penetration when there is a pressure drop across the substrate. That there is a pressure drop and not a uniform pressure inside the fabric is clear from the fact that penetration indeed increases when pressure is increased.

Besides a pressure change resulting from a lower foam density, a change of structure will also occur, the influence of which needs to be studied separately. Less drainage and higher foam viscosity might be expected to lead to a lesser degree of penetration instead of the higher degree found. Contrary to results reported by Herlinger et al. [5], drainage was indeed found to accelerate at higher foam densities (Figure 5).

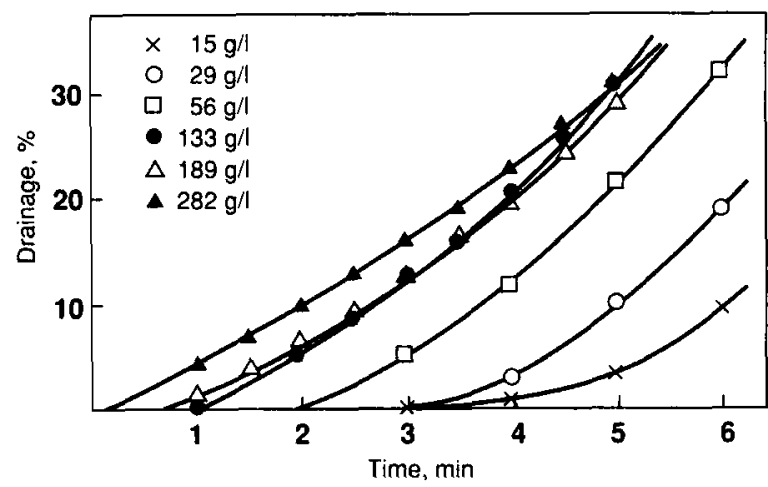

Figure 5 - Rates of foam drainage at different initial foam densities (10 g/l sodium $n$-dodecyl sulphate)

The influence of contact with the textile substrate on drainage (substrate active) was not studied in this investigation. Further comparison of the three series mentioned in Figure 5 is difficult because more parameters were varied. Nevertheless, when comparing series 1 and 3 it is possible that, despite the higher (liquid) viscosity, the degree of penetration was considerably higher in the third series, possibly caused by the higher velocity.

\section{Viscosity}

The influence of liquid viscosity (Table 3) was determined comparing the foamed solutions LS20 and LS30.

In spite of relatively small difference in viscosity (a factor of six in the liquid phase at $1 \mathrm{~s}^{-1}$ and $1.5-3.0$ at higher shear rates and variable foam densities) a larger degree of penetration can clearly be seen at lower viscosities. It is probably possible to obtain higher degrees of penetration

\section{TABLE 3}

\section{Penetration as a function of liquid viscosity}

\begin{tabular}{lcccccc}
$\begin{array}{l}\text { Liquid Penetration } \\
\text { system }\end{array}$ & $\begin{array}{c}\text { Wet } \\
\text { pick-up }\end{array}$ & $\begin{array}{c}l \\
(\mathrm{~mm})\end{array}$ & $\begin{array}{c}\rho \\
(\mathrm{g} / \mathrm{l})\end{array}$ & $\begin{array}{c}v \\
(\mathrm{~m} / \mathrm{min})\end{array}$ & Mode \\
\hline & & & & & & \\
LS20 & 70 & 30 & 2.25 & 333 & 20 & Coating \\
LS30 & 60 & 30 & 2.25 & 333 & 20 & Coating \\
LS20 & 69 & 30 & 2.25 & 200 & 6.7 & Coating \\
LS30 & 66 & 30 & 2.25 & 200 & 6.7 & Coating
\end{tabular}


using less thickener or none at all in the liquid phase because in that way a decrease in viscosity by a factor of five in the foam phase and over 100 in the liquid phase is possible.

\section{Velocity-contact time}

In Table 4 the results of experiments determining the dependence of penetration on contact time, and the two independent variables of which it is composed, fabric velocity and the length of the application slit, are shown.

\section{TABLE 4}

Relationship between penetration, contact time, velocity and contact length (a)

\begin{tabular}{cccc}
\hline $\begin{array}{c}l \\
(\mathrm{~mm})\end{array}$ & $\begin{array}{c}t_{c} \\
(\mathrm{~ms})\end{array}$ & $\begin{array}{c}v \\
(\mathrm{~m} / \mathrm{min})\end{array}$ & $\begin{array}{c}\text { Penetration } \\
(\%)\end{array}$ \\
\hline & & & \\
2.25 & 5.3 & 25.6 & 75 \\
2.25 & 20 & 6.7 & 60 \\
5.5 & 13 & 25.0 & 78 \\
5.5 & 20 & 16.2 & 67 \\
5.5 & 49 & 6.7 & 60 \\
18.2 & 49 & 22.2 & 70 \\
\hline
\end{tabular}

(a) Mode of application: 20\% wet pick-up, LS30, $\rho_{\mathrm{s}}=200 \mathrm{~g} / \mathrm{l}$, no screen

A clear relationship between penetration and contact time could be found, as presumably it would be overshadowed by other effects. However, there were too few observations to enable us categorically to state that there is no relationship at all when varying the contact time by changes in the contact length.

The relationship between penetration and velocity alone is very clear (Figure 6). Increasing speed results in a proportional increase of the foam flow perpendicular to the fabric. Thus the foam will be pressed into the fabric under greater pressure, resulting in a greater degree of penetration. What the effects of higher shear rates and shorter contact times will be cannot be observed because they are overshadowed by the effect of the greater pressure.

The pressure increase can be compared with that appearing in conventional processes with a doctor blade, knife or roller. In these cases the increase in flow will be lower, resulting in lower pick-up.

The concept of an equilibrium contact time and dynamic sorption rate as defined by Bryant [4] cannot be used because it deals with limiting situations where no pressure drop exists.

\section{Foam printing}

The effect of wet pick-up on the degree of coloration of a $1 \mathrm{~mm}$ wide line was mentioned earlier. At too low a fabric velocity it was not possible to obtain a level printing, but any further influence of fabric velocity variations was not found. Lowering the foam density at constant wet pick-up resulted in better levelness and more coloration of the blank line (besides higher penetration). This observation

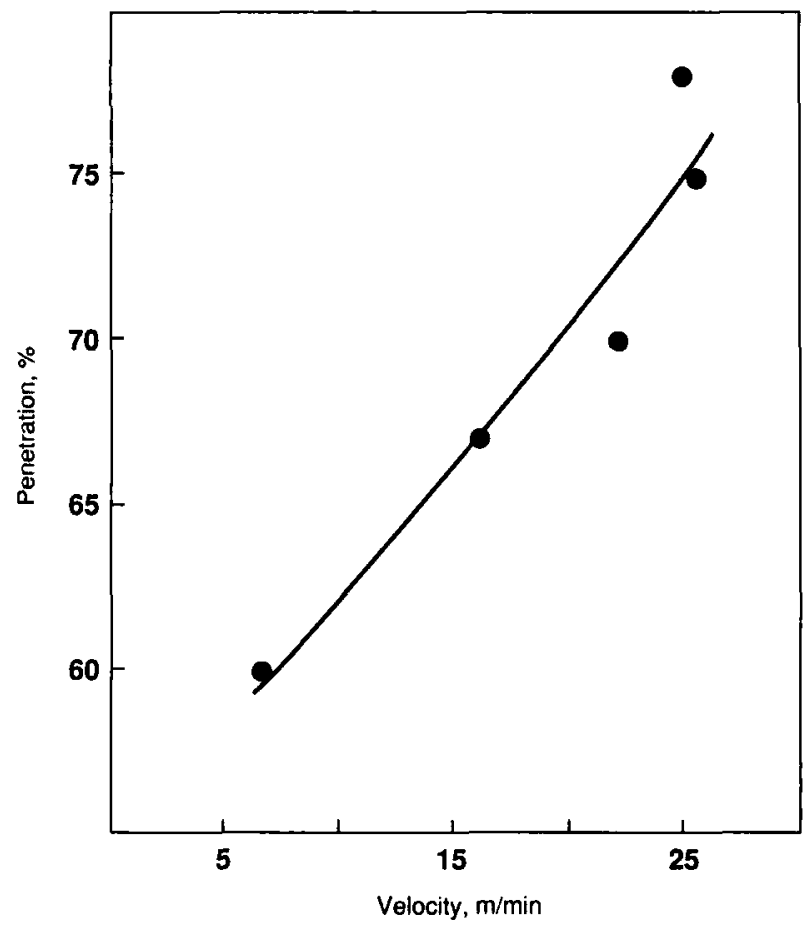

Figure 6-Penetration as a function of fabric speed

again indicates the importance of the large volume of foam. This effect of foam density was even observed at a wet pick-up of $15 \%$, where no planar transport would be expected to take place. On lowering the density from 333 to $100 \mathrm{~g} / \mathrm{t}$ the line gradually became more coloured.

The observations for foam printing (with a screen) and dyeing (without any screen at all) agree inasmuch as they both indicate the major importance of the total amount of liquid being applied. Also in foam application the capillary transport in the yarns and fibres plays an important role. Observations on the other parameters indicate a certain contribution originating from the air added. Because it is possible to press the foam right through the fabric, a contribution to transport in the foam phase is plausible, in addition to the necessarily fast degradation that follows from the considerations on the volume ratio of foam to fabric (Figure 3).

\section{EVALUATION}

With a closed foam application system it is possible to apply a known quantity of chemicals in water onto a moving substrate. The flow and the distribution of liquid and chemicals at any instant are dependent on the substrate, the mode of application and a number of process variables. With this knowledge it becomes possible to describe the process, make it run more efficiently and control it to give a better product. Arriving at such a process description calls for the effects of the relevant parameters to be known.

In this investigation foam was added to cotton via a fixed application slit. The influence of several parameters on the penetration of water was studied by determining the reflectance of the substrate caused by a colorant added to the liquid as a tracer for its transport mechanism. From this the major importance of the absolute amount of liquid used is very clear. The degree to which capillary transport is possible is very important. Other parameters having significant influence are liquid viscosity, foam density and 
fabric speed. In broad outline their influence can be explained (at constant wet pick-up) but more research will be necessary to provide insight into the fundamental mechanisms of foam degradation and transport in the substrate.

It is not totally clear to what extent the liquid viscosity influences the liquid transport in the capillary system of the fabric or the viscosity change in the foam phase. Nevertheless, liquid viscosity is an interesting parameter because by controlling it the foam viscosity can be varied independent of flow. On the contrary, changing foam viscosity by varying the foam density causes proportional changes in flow. Therefore variations in foam density and fabric speed must be ascribed mainly to the effects of foam flow and the resulting pressure increase. Hence it is not possible to evaluate fully the effects of structural changes and shear rate.

By using a constant wet pick-up the present results cannot readily be compared with those of Fiebig et al. [6] because the latter relate to an open foam system, so that wet pick-up levels varied with foam density. Their measure for penetration, called two-sidedness, was accordingly not defined, but it can be compared to the penetration defined in Eqn 1. The larger the degree of two-sidedness they found, as a function of lower foam densities, was contradictory to the results from the present investigation. Yet it is very doubtful to what extent this conclusion may be ascribed to the effect of foam density because the wet pickup also decreases, resulting in a larger degree of twosidedness.

Another parameter that undoubtedly will explain some of the results is the exact pressure with which the foam is pressed through the substrate. It is possible that a more direct relationship between penetration and foam pressure would be found than with other parameters studied. Measurements on pressure will therefore be part of further investigations.

The relevance of the results presented can perhaps best be emphasised in a comparison with conventional processes. In finishing and dyeing the wet pick-up has no real meaning but is replaced by an exchange coefficient, a quantity also incorporating the absorption characteristics of the fabric. While foam processing is not an exchange process, but a one-way application of a limited amount of solution, a range of parameters assume a completely new bearing. Wet pick-up comes into play, determining the transport possibilities by limiting them to a certain degree. Foam density becomes important in relation to the available fabric volume. Viscosity bears a double significance, determining the flow properties of the foam as well as the resulting solution delivered.

The pressure applied to drive the foam into the fabric also has a different significance than has the squeezing of the fabric in a bath to promote impregnation.

The significance of all these separate parameters comes down to one phenomenon: the interaction of the absorption of a fabric with foam breakdown. This will not only be of interest to all types of foam application but also to conventional processes where the lack of sufficiently strong absorption causes problems.

This research was supported by the Netherlands Technology Foundation (STW).

\section{REFERENCES}

1. J J de Boer, TNO Delft (Fibre Institute) internal report (1987).

2. P Kubelka and F Munk, Z. Tech. Physik., 12 (1931) 593.

3. H J L J van der Linden, PhD thesis, University of Twente (1984).

4. G M Bryant, Text. Research J., 54 (1984) 217.

5. H Herlinger et al., Textil Praxis, 40 (1985) 495

6. D Fiebig et al., Textil Praxis, 42 (1987) 269.

7. A B J Kroezen, J.S.D.C., 104 (1983) 393.

\section{LIST OF SYMBOLS}

$\begin{array}{lll}\begin{array}{ll}\text { Symbol } \\ B\end{array} & \begin{array}{l}\text { Quantity } \\ \text { Blow ratio = volume of gas/ } \\ \text { volume of liquid, related to } \rho_{\mathrm{s}}\end{array} & \\ & \text { by Eqn 1 } & \\ h & \text { Height } & \mathrm{mm} \\ l & \text { Length } & \mathrm{mm} \\ P & \text { Penetration according to Eqn } 2 & \% \\ t_{\mathrm{c}} & \text { Contact time } & \mathrm{ms} \\ v & \text { Velocity of cloth and rubber belt } & \mathrm{m} / \mathrm{min} \\ w & \text { Width } & \mathrm{mm} \\ \eta & \text { Viscosity } & \mathrm{Pa} \mathrm{s} \\ \rho_{\mathrm{s}}, \rho & \text { Foam density } & \mathrm{g} /\end{array}$

